THURSDAY, DECEMBER 28, $187 \mathrm{I}$

\section{TECHNICAL EDUCATION IN HOUSE CONSTRUCTION}

$\mathrm{R}$ FERRING to the recent sad events at Londesborough Lodge, and the disclosures made in the medical press, showing how the whole internal air of this house was tainted with sewer gas for want of ordinary care, the Times, in an able article which appeared on December 9 , has the following telling passage : "What a satire on the universal diffusion of knowledge, on the lectures of the Royal Society, on hundreds of scientific and educational institutions, and all our new inventions and discoveries! Here is the simplest thing in the whole world, which wanted only common sense, and nobody seems to have thought of it-nay, we are not sure that our architects and builders will be thinking of it next year. It is far too simple and too deadly an affair."

We purpose to deal with this subject; and in doing so to show briefly how it is that with every apparent advantage our houses are still not altogether safe to live in.

In the first place, the whole subject of house-drainage has been thoroughly discussed, and simple rules have been laid down, which any one with ordinary technical skill can apply to any conceivable case.

The question has been treated in published reports by the Health of 'Towns' Commission, by the Metropolitan Sanitary Commission, by the General Board of Health, by the Barrack and Hospital Improvement Commission, by the Local Government Act Office, and recently, by the Army Sanitary Commission, for application in India. These official documents, extending over a period of nearly thirty years, contain all the principles on which wholesome house-conveniences can be constructed; and besides all this, engineering, architectural, and medical journals have never ceased to advocate attention to the requirements of healthy house construction. The Legislature, on its side, has been anxiously engaged in defining and granting every necessary power for the efficient carrying out of town-drainage works; but hitherto these powers have stopped short with the house drain. All between the head of the house drain and the interior of our bedrooms has been left to chance, or to the imperfect know ledge or no knowledge of such officials as we have seen lefending the deadly arrangements of existing houses, or to plumbers' journeymen or apprentices. The whole experience shows that every official has considered his 1uty fulfilled when he had ensured an outlet for the refuse water of the house. As to the subsidiary traps, and such like things, they have been introduced without regard to scientific considerations; so that, instead of proving an advantage, they have, in some instances, increased the evil. Now, it must henceforth be recognised that house drainage is not a question of hydraulics merely, it is in a higher sense a question of pneumatics; but even in this extended sense it is far from being a difficult art, as some would have us suppose. It is by no means a "refuge of despair," as some have asserted. It is a great and beneficial necessity. Because carelessly-fitted water-pipes are burst by frost, and our houses are deluged every voL. v. winter, are we to have a crusade against water supply? Bursting of water-pipes and the influx of foul air from sewers are indications of want of ordinary common sense; or, at all events, of very ordinary technical skill. And the real future question before us, is not whether we are to abolish household drainage and water supply, but whether some public control in these matters ought not to be exercised over the proceedings of plumbers' apprentices and other similar persons, so that when we rent or buy a house, we may be assured that typhoid fever, or some other pestilence, is not included in the contract. Every such contract should, however, ensure three things, viz., that water-pipes are protected from frost; that the house is thoroughly drained; and that no sewerair can, under any circumstances, enter the house. Now all these things can be assured.

It is a mere truism to say that there are plenty of nonconductors of heat with which water-pipes can be efficiently surrounded. Why should water-pipes be left uncovered under flooring or in walls, as at present? Surely any local authority could deal with so simple, and, at the same time, so important a question as this,

As regards efficient drainage-pipes, traps, and the like, there are great manufacturing interests inv ${ }^{r}$. " in the production of these, and any one who will , n eye over the advertising columns of orr archit $\quad 1$ and engineering contemp

and wholesome compesion w...

¿nuity

oduction

of the most scientific forms of apparatus of this class. But the missing link in the whole of these drainage arrangements is how to prevent foul air entering the house. In an ordinary second or third-class house in London, there are three or four water-closets, the main pipe from which enters the drain, either directly or through an inefficient trap. It may be safely stated that at all times there is more or less pressure of sewer air on the pan or trap of the closet, which must lead to an infiltration of foul air into the house. But nobody appears to have applied the long-known remedy for this, viz., to take off the pressure by a small leaden pipe carried from the upper end of the soil-pipe to the open air.

It is not, however, from the soil-pipe that most of the danger arises. Houses of the same classes have generally what is called a safe under the water-closet, from which safe a pipe passes directly to the drain. Next there may be a bath with its outlet pipe, its overflow, and the pipe of its safe, all connected with the drain. There may be three or even four sinks all connected with the drain, and then every cistern has its overflow, also connected with the drain. As these various open pipes are distributed all over the house, we can easily understand how, while fulfilling the function of removing waste water, they may, in conformity with the laws of pneumatics, distribute the most deadly poison among the unconscious sleeping inmates of every bed-room.

Foul sewer air returns into a house for the following reasons, viz. :- - . A wind-pressure exercised on the open mouth of a sewer perhaps many miles away; or a similar pressure exerted on an ordinary gulley grate. 2. By pressure of foul air into the house from the superior specific gravity of the atmosphere outside. 3. The draft of chimneys, when doors and windows are shut, as during the night. This draft must be supplied, and will supply 
itself from every one of these small pipes, perhaps a dozen or more in a house, if it cannot be supplied more easily elsewhere.

The principles to be kept in view in dealing with defects such as those stated are obvious enough.

The general drain system of every street or district should be studied as regards its pneumatic relations, and means should be adopted for relieving the pressure within the system by ventilating outlets in safe positions. By placing charcoal strainers at all these outlets, sewer air would be deprived of its destructive qualities before passing into the streets. In special cases provision would have to be made for preventing the tide or strong winds from entering the mouth of the main sewer.

Then as regards the household drains. There is nothing easier than to ventilate the soil-pipes through charcoal filters in the manner stated. And as regards the numerous small pipes of sinks, baths, \&c., not one of these ought on any account to communicate directly with a sewer. They ought all to be collected and allowed to discharge their contents in the open air over a trap communicating with the house drain, so that reflux of sewer gas into the house would be simply impossible.

Much evil has in times past arisen from imperfect drains within houses. Properly there should be none such. All connections of water-closets, sinks, baths, \&c., with the house drain, should take place outside the house walls, and where from bad construction drains have been laid within houses and cannot be altered, they should be replaced by glazed earthen pipes laid in concrete, every joirst made perfectly air-tight.

Cess-pits and traps ought never to be permitted within walls. The trapping should be all outside.

From want of attention to these long-known principles most of our houses are sick, and require separate diagnosis and treatment. They can all be cured if we only could find an authority to undertake the cure.

Were it not that in many instances we should have men of straw to deal with, we should feel disposed to advocate the application of Lord Campbell's Act to these cases. But as the recovery of damages would be a remote contingency, why should not Local Boards of Health, with their highly-paid health officers and surveyors, be required to see not only that all the details of water supply and drainage in new houses are safe, but that unsafe houses are made safe by their proprietors, or condemned as unfit for habitation?

After all is done, however, the chief remedy must be sought in technical training on all house questions in the application of which scientific principles are involved.

It may be safely stated that there is no technical subject of greater importance than this, and our recent experience has shown that there is no subject on which more training is necessary than to build a comfortable healthy dwelling.

\section{SUTTON'S VOLUMETRIC ANALYSIS}

Volumetric Analysis. By $F$. Sutton. Second Edition. (London: J. and A. Churchill.)

THE present volume is almost the only representative $I$ of a considerable branch of chemistry. We are surprised that Volumetric Analysis has not come into more general use amongst chemists, for the saving of time in most instances is very great, whilst for accuracy it frequently surpasses gravimetric analysis. Since the last edition of this work was published (1863), chemistry has made great advances ; in volumetric analysis there has been a gradual extension and development, although nothing very new or startling has taken place during this period. This edition is a far more handsome volume than the last, the type and engravings being everything that can be desired. The author states in his preface that the new system of atomic weights has been adopted; the nomenclature also has been changed to a great extent, although we are sorry to find that the system adopted is by no means perfect. Thus we read of "the carbonates of lime, baryta, and strontian" (p. 26), whilst in a later part of the book such terms as " hydric chloride," \&c., are met with. These of course are extreme cases; would it not have been better to have adopted some definite system throughout the book? We regret to say that the larger portion of the book is disfigured by a great number of small errors; for instance, the cross references in many cases are wrong, thus at page 80 , the reader is referred to $\S 80,2$, for the determination of chlorides by Liebig's method, the paragraph referred to is an article "on the examination of raw phosphates and phosphatic manures." Again, we are told on p. ir6 to refer to $\$ 7 \mathrm{r}$ for the titration of phosphate, but this paragraph describes the estimation of sulphuretted hydrogen. We have noticed so many errors, some in formulæ, some in equations, and again in grammar, that, though making every allowance for printer's errors, we must conclude that the edition has been carelessly revised. There is one paragraph we should wish to call attention to, the first on p. 132, which we confess we have not been able to understand clearly. The number of new processes introduced is not large, nor are they of very great importance. We think, however, that methods such as the estimation of nitric acid by indigo might have been omitted, and that, for instance, the iron process for phosphoric acid might have been introduced. If Mr. Sutton would give, as far as possible, the precise cases for which each process is most suitable, we think the value of the book would be much increased. His long experience in these matters would render this addition of great importance, and would save much trouble.

Fifty-four pages of the volume are occupied by a description of the processes of water analysis (furnished by Mr. W. Thorp); this consists of a lengthy description of Frankland and Armstrong's process, which has undergone considerable modification, and a much shorter description of Wanklyn and Chapman's process. We look upon this part of the book as very valuable, for water analysis has now become quite a study, and such a clear and concise statement as that in the present volume will be found of great service to any one engaged in this work.

The last section of the book, consisting of seventy.four pages, is "On the Volumetric Analysis of Gases," contributed by Prof. H. McLeod. We cannot praise this portion of the volume too highly, the engravings are excellent, many of them we believe being from the original drawings of the author. We do not think that any student could do better than take this as his guide to gas analysis. It is the most clearly written and practical 